\title{
Simultaneous resolution of febuxostat and diclofenac potassium in pure form and in their multi-ingredient formula
}

\author{
Shimaa A. Mahmoud ${ }^{1 *}$, Amira M. El-Kosasy ${ }^{2}$ and Fatma A. Fouad \\ ${ }^{1}$ Pharmaceutical Analytical Chemistry Department, Faculty of Pharmacy, Al-Azhar University, Cairo, Egypt. \\ ${ }^{2}$ Pharmaceutical Analytical Chemistry Department, Faculty of Pharmacy, Ain Shams University. \\ *Correspondence: shimaa.ahmed22@azhar.edu.eg
}

Article history: Received: 07-06-2021

Revised:14-07-2021

Accepted: 03-08-2021

\begin{abstract}
Easy, precise, and accurate three spectrophotometric procedures for successive resolution of febuxostat and diclofenac potassium in their multi-ingredient formula without prior separation were established and validated. Second derivative $\left({ }^{2} \mathrm{D}\right)$, dual-wavelength (DW), and ratio subtraction (RS) are the names of these procedures. They showed good linearity in the ranges of $2.0-20.0 \mu \mathrm{g} / \mathrm{mL}$ for febuxostat and $5.0-50.0 \mu \mathrm{g} / \mathrm{mL}$ for diclofenac potassium with strong determination coefficients $\left(r^{2}\right)$. For ${ }^{2} \mathrm{D}\left(\mathrm{r}^{2}=0.9995-0.9998\right)$, DW $\left(\mathrm{r}^{2}=\right.$ $0.9997-0.9998)$ and RS ( $r^{2}=0.9995$ - 0.9999) for febuxostat and diclofenac potassium; respectively. By using the proposed procedures, the limits of detection and the limits of quantitation for febuxostat and diclofenac potassium were $0.135-0.580 \mu \mathrm{g} / \mathrm{mL}$ and $0.408-1.756 \mu \mathrm{g} / \mathrm{mL}$, respectively. They were also successfully used to test two drugs in their multi-ingredient formula, with the findings being checked, statistically analyzed, and found to be consistent with those obtained by a previously published method.
\end{abstract}

Keywords: Febuxostat; Diclofenac; Dual-wavelength; Second derivative; Ratio subtraction.

\section{Introduction}

Febuxostat (FEB) is 2 (3-cyano 4-[2-methyl propoxy] phenyl) 4 methyl-1, 3-thiazole 5-carboxylic $\operatorname{acid}^{1}$ (Figure 1a). It works as a xanthine oxidase inhibitor and can be used to treat hyperuricemia and chronic gout ${ }^{2}$. It is a nonpurine selective xanthine oxidase inhibitor. FEB was found to be more effective than allopurinol at lowering serum uric acid levels ${ }^{3}$. Some drug forms containing an NSAID such as diclofenac potassium (DIC) are co-formulated to reduce inflammation and control pain in gout attacks. DIC is the salt of potassium 2-(2, 6-dichloranilino) phenyl acetic acid $^{1}$ (Figure 1b). Few analytical techniques for simultaneous study of FEB and DIC were found in the literature review. These methods include: spectrophotometry ${ }^{4-7}$, HPTLC ${ }^{7,8}$ and HPLC methods 9,10 .

\subsection{Theoretical background of the suggested procedures.}

1.1.1. Derivative spectrophotometry is a benefit analytical method for extracting qualitative and quantitative data from overlapping curves, as well as removing the effects of standard shifts and standard tilts induced by finding other compounds in a sample. The properties recorded can permit evaluation of one or a few analytes without first separating or purifying them $^{11}$. Derivative spectrophotometry has become very useful in recent years as an additional method for resolving various analytical problems. It's used in a variety of fields, including pharmaceutical, forensic, clinical, and biochemical analysis, as well as inorganic and organic analysis ${ }^{12}$. Furthermore, the second derivative procedure can be used to evaluate drug substances in the presence of impurities by choosing a wavelength with no influence from the impurity (zero crossing) and a suitable value for the drug to be measured. For the assay of drugs in mixtures and multi-ingredient formulas, it has become a well-established technique ${ }^{13,14}$

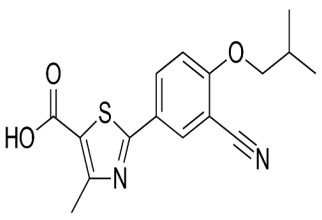

(a)

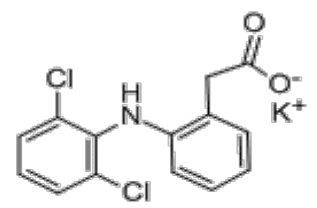

(b)
Figure 1: Chemical structures of (a) Febuxostat and (b) Diclofenac potassium (Sweetman $\mathrm{SC}^{1}$ ).

Cite this article: Mahmoud, S., Fouad, F., EL-Kosasy, A. Simultaneous resolution of febuxostat and diclofenac potassium in pure form and in their multi-ingredient formula.. Azhar International Journal of Pharmaceutical and Medical Sciences, 2021 ; 1 (3): 75 - 83. doi: 10.21608/aijpms.2021.79525.1080 
1.1.2. Dual wavelength: In the presence of an interfering object, dual wavelength spectroscopy is an effective technique for analysing a component. Dual analytical wavelengths were chosen to eliminate interference by making the absorbance difference zero for one drug when analysing the other ${ }^{15-17}$.

1.1.3. Theory of ratio subtraction technique ${ }^{18-21}$ The method is dependent on this; in case you have a mixture of two drugs (A) and (B) with overlapping spectra and (B spectrum) is extended than (A), you can determine (A) by dividing the mixture's spectrum by a certain concentration of $(\mathrm{B})$ as a divisor ( $\left.\mathrm{B}^{\prime}\right)$. (A / $\mathrm{B}^{\prime}+$ constant) would be the new curve as a result of the division. We can get the original curve by subtracting this constant, then multiplying the new curve obtained after subtraction by ( $\left.\mathrm{B}^{\prime}\right)$ (The divisor). This may be summarized within taking after equations ${ }^{18-21}$.

$$
\begin{aligned}
& (\mathrm{A}+\mathrm{B}) / \mathrm{B}^{\prime}=\left(\mathrm{A} / \mathrm{B}^{\prime}\right)+\left(\mathrm{B} / \mathrm{B}^{\prime}\right)=\left(\mathrm{A} / \mathrm{B}^{\prime}\right) \\
& + \text { Constant }
\end{aligned}
$$

$$
\left(\mathrm{A} / \mathrm{B}^{\prime}\right)+\text { Constant }- \text { Constant }=\left(\mathrm{A} / \mathrm{B}^{\prime}\right)
$$

$$
\left(\mathrm{A} / \mathrm{B}^{\prime}\right) \times\left(\mathrm{B}^{\prime}\right)=(\mathrm{A})
$$

The constant can be calculated from the curve $(A+B)$ / $\mathrm{B}^{\prime}$ by the straight line which is parallel to the wavelength axis within the region where (B) is extended.

\section{Methods}

\subsection{Instrumental}

All absorbance estimations were performed with a Shimadzu UV Vis 1601 PC spectrophotometer (Tokyo, Japan) associated to an IBM compatible device and an HP laser jet printer, and a quartz cell with a $1 \mathrm{~cm}$ path length. UV- Probe personal spectroscopy software version 2.21 (Shimadzu) is the included software. The speed of scanning is 2800 $\mathrm{nm} / \mathrm{min}$ and the band spectral is $2 \mathrm{~nm}$.

\subsection{Chemicals \& reagents}

- Pure febuxostat: B. No. OP-FAB/06/16/001 was kindly provided by Mash Premiere with purity $100.61 \%$ according to supplier.

- Pure diclofenac potassium: B. No. DK/ 1808 /0080B was kindly provided by The Arab Company for Gelatin \& Pharmaceutical products with purity $99.85 \%$ according to supplier.

- Methanol (Sigma - Aldrich, USA) analytical grade. -Pharmaceutical multi-ingredient formula

- Xanfeb DSR ${ }^{\circledR}$ tablets, it is labelled to contain $40 \mathrm{mg}$ FEB and $100 \mathrm{mg}$ DIC manufactured by Indoco Remedies, India) were purchased from pharmacies.

\subsection{Standard solutions}

FEB \& DIC stock standard solutions were made with methanol at a concentration of $1 \mathrm{mg} / \mathrm{mL}$. The stock solutions were diluted with methanol to prepare the working solutions of both drugs at a concentration of $(100 \mu \mathrm{g} / \mathrm{mL})$.

\subsection{Procedures}

\subsubsection{Spectral characteristics}

Utilizing methanol as a blank, ${ }^{0} \mathrm{D}$ of FEB (2.0$20.0 \mu \mathrm{g} / \mathrm{mL})$ and DIC $(5.0-50.0 \mu \mathrm{g} / \mathrm{mL})$ were recorded over the extend of $200-400 \mathrm{~nm}$ and put away within the computer. The stored data were subjected to different procedures to obtain second derivative spectra $\left({ }^{2} \mathrm{D}\right)$, dual wavelength $(\mathrm{DW})$ and ratio subtraction spectrophotometry (RS).

${ }^{2} \mathbf{D}$ spectra of the drugs were recorded and the peak amplitude at $353 \mathrm{~nm}$ for FEB and $246 \mathrm{~nm}$ for DIC (Figures 2,3) was calculated using scaling factor 300 and $=16000$ against methanol as a blank.

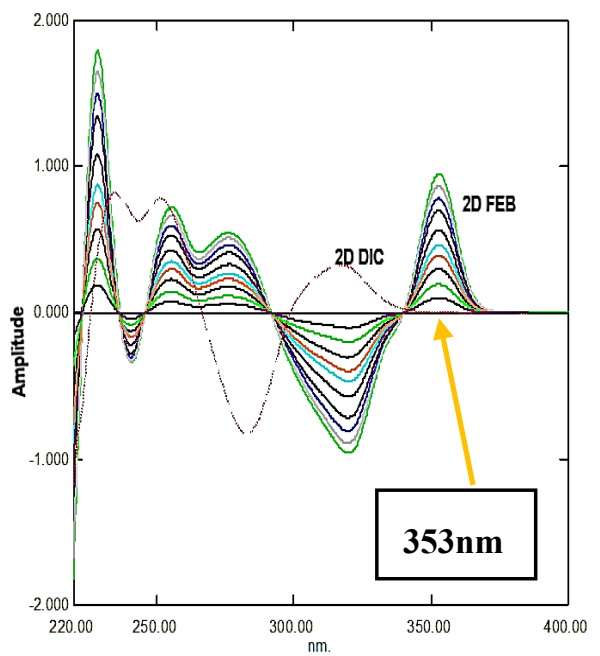

Figure 2: Second derivative of different concentrations of FEB spectra $(2-20 \mu \mathrm{g} / \mathrm{mL})$ at $353 \mathrm{~nm}$ and second derivative of DIC $(20 \mu \mathrm{g} / \mathrm{mL})$.

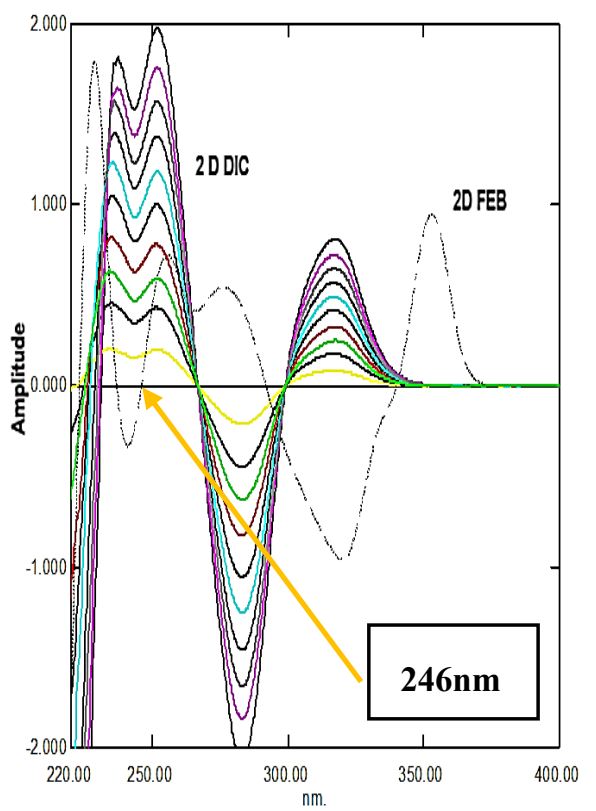

Figure 3: Second derivative of different concentrations of DIC spectra $(5-50 \mu \mathrm{g} / \mathrm{mL})$ at $246 \mathrm{~nm}$ and second derivative of FEB $(20 \mu \mathrm{g} / \mathrm{mL})$.

DW method was chosen for a mixture of two drugs because it allowed for a zero-absorbance difference for one drug and a high absorbance difference for the 
other. The spectra of the prepared standard solutions are scanned from 200 to $400 \mathrm{~nm}$. FEB \& DIC solution absorbance differences were estimated at 299.8 and $265 \mathrm{~nm}$ or 279.8 and $249.2 \mathrm{~nm}$ for FEB \& DIC, respectively (Figure 4).

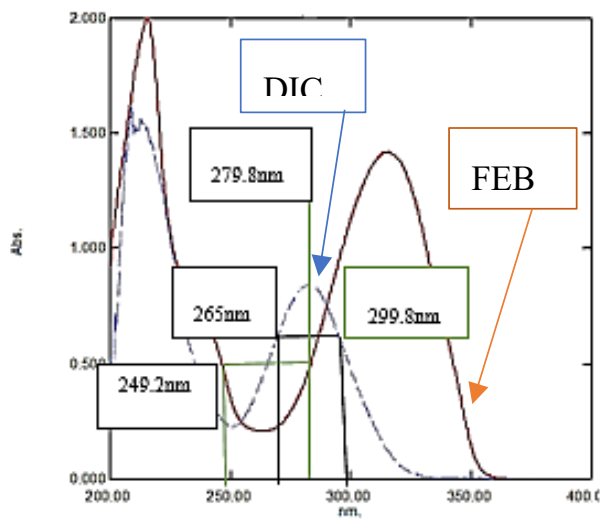

Figure 4: Zero order spectra of $(20 \mu \mathrm{g} / \mathrm{mL})$ of FEB \& DIC in methanol.

RS procedure, to obtain the ratio spectra, divide the stored FEB spectra by the spectrum of DIC $(20 \mu \mathrm{g}$ $/ \mathrm{mL}$ ) (Figure 5A). The constant was subtracted from every ratio spectrum (the value of amplitude at 271 $\mathrm{nm}$ in the ratio spectra), then the obtained spectra were multiplied by the divisor spectrum (Figure5B). At $316 \mathrm{~nm}$, the amplitude values were calculated (Figure 5C). To determine DIC, divide the stored DIC spectra by the spectrum of FEB $(20 \mu \mathrm{g} / \mathrm{mL})$ to obtain the ratio spectra (Figure 6A). The constant was subtracted from every ratio spectrum (amplitude value at $321 \mathrm{~nm}$ in the ratio spectra), then the spectra obtained were multiplied by the divisor spectrum (Figure 6B). At $283 \mathrm{~nm}$ the amplitude values were measured. (Figure 6C).

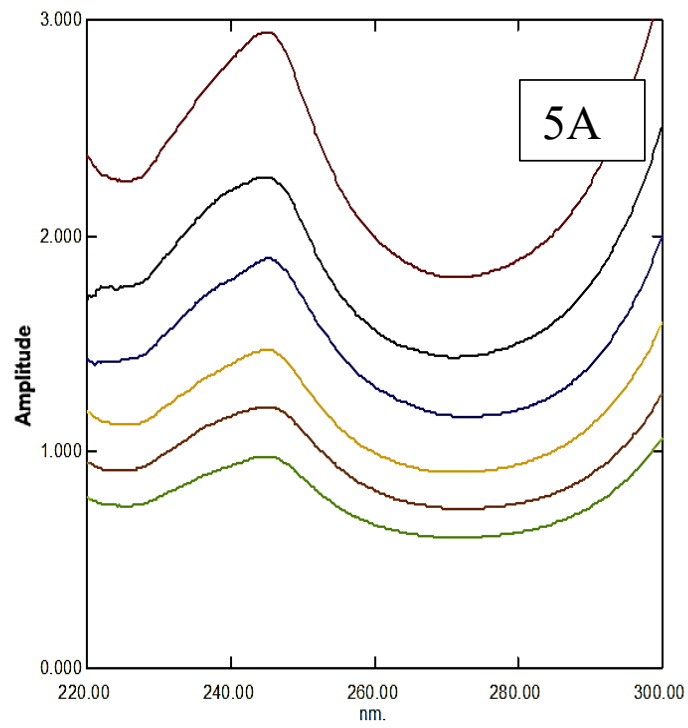

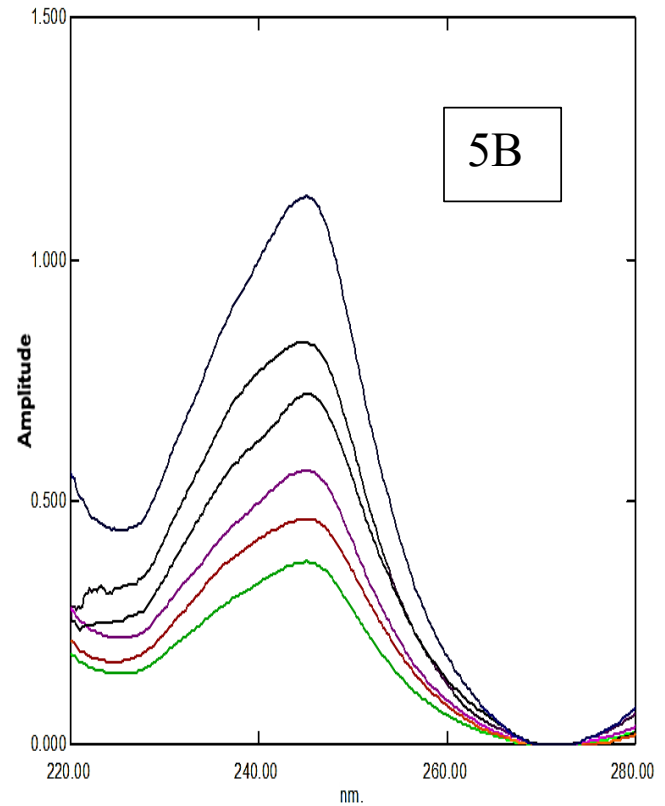

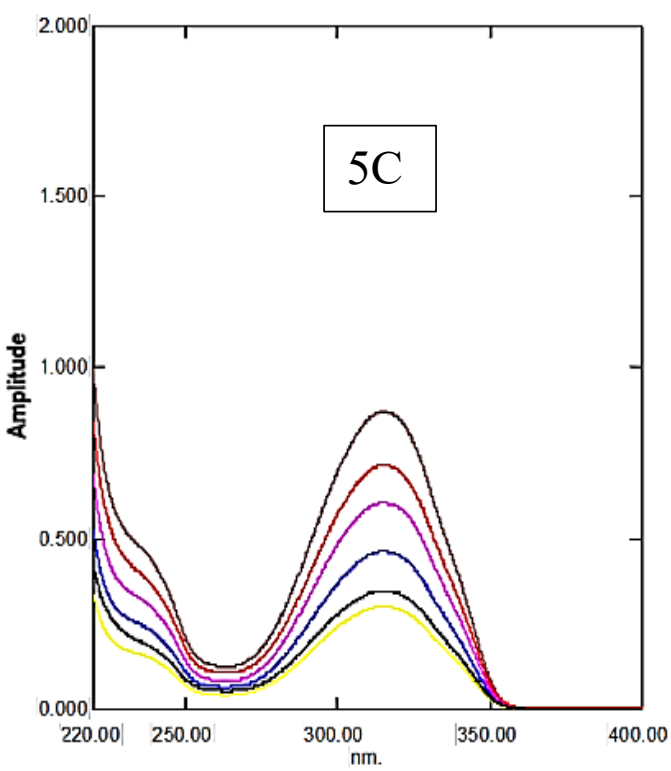

Figures 5: Ratio spectra of laboratory prepared mixture of FEB and DIC (A): After using $(20 \mu \mathrm{g} / \mathrm{mL})$ of DIC as divisor. (B): After subtraction of the constant at $271 \mathrm{~nm}$. (C): After multiplying by the divisor again. 

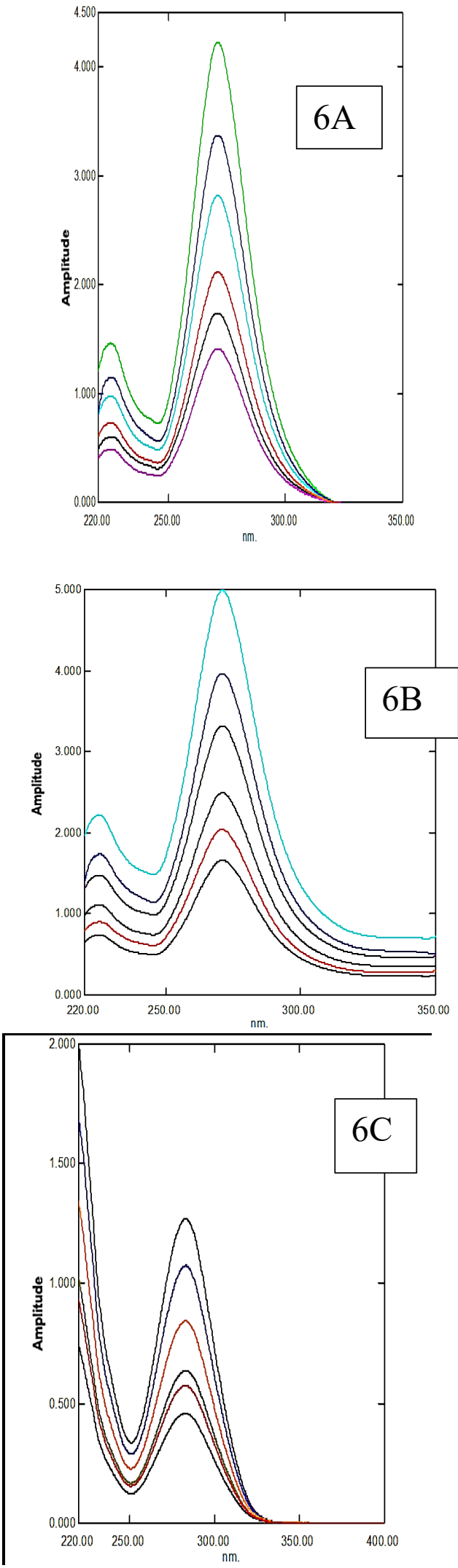

Figures 6: Ratio spectra of laboratory prepared mixture of FEB and DIC (A): After using $(20 \mu \mathrm{g} / \mathrm{mL})$ of FEB as divisor. (B): After subtraction of the constant at $321 \mathrm{~nm}$. (C): After multiplying by the divisor again.

\subsubsection{Laboratory prepared mixtures}

Mixtures of different ratios for FEB \& DIC were developed by taking aliquots from the corresponding working solutions $(100 \mu \mathrm{g} / \mathrm{mL})$, mixing well, and volume was completed with methanol to be analysed by the proposed methods.

${ }^{2} \mathbf{D}$ procedures, FEB or DIC concentrations determined from the corresponding regression equation by measuring peak amplitude at $353 \mathrm{~nm}$ or at $246 \mathrm{~nm}$ for FEB or DIC; respectively.

DW The absorbance difference calculated between at 299.8 and $265 \mathrm{~nm}$ or at 279.8 and 249.2 $\mathrm{nm}$ for FEB or DIC; respectively and the concentrations of the drug were calculated from the corresponding regression equation.

RS procedures for calculation of FEB the absorption spectra of two drugs were divided by that of DIC $(20 \mu \mathrm{g} / \mathrm{mL})$, to get the ratio spectra. The constant (amplitude value at $271 \mathrm{~nm}$ in the ratio spectra) was subtracted from each ratio spectrum, followed by multiplication of the obtained spectra by the divisor spectrum and the amplitude values were measured at $316 \mathrm{~nm}$ (Figures 5A, B and C). While for determination of DIC, the absorption spectra of mixture were divided by that of FEB $(20 \mu \mathrm{g} / \mathrm{mL})$, to get the ratio spectra. The constant (amplitude value at $321 \mathrm{~nm}$ in the ratio spectra) was subtracted from each ratio spectrum, followed by multiplication of the gotten spectra by the divisor spectrum and measuring the amplitude values at $283 \mathrm{~nm}$ (Figures 6A, B and C).

\subsubsection{Pharmaceutical multi-ingredient formula}

Ten tablets of Xanfeb DSR $®$ were adequately weighed and pulverized. In a 50-mL volumetric flask, a quantity of powder equivalent to $80 \mathrm{mg}$ FEB or 200 $\mathrm{mg}$ DIC was transferred. A volume of $25 \mathrm{~mL}$ methanol was applied to the flask, which was sonicated for 30 minutes before being completed to volume with methanol followed by filtration. One milliliter of this solution was diluted in $100 \mathrm{~mL}$ of methanol to yield a final solution containing $16 \mu \mathrm{g}$ $/ \mathrm{mL}$ FEB or $40 \mu \mathrm{g} / \mathrm{mL}$ DIC. The nominal contents of the tablets were calculated utilizing the corresponding regression equations or the previously plotted calibration graphs.

\section{Results}

\subsection{Methods Validation}

The developed spectrophotometric methods were validated using the guidelines of $\mathrm{ICH}^{22}$.

\subsubsection{Linearity}

Aliquots of standard FEB and DIC solution $(100.0 \mu \mathrm{g} / \mathrm{mL})$, equivalent to $(2.0-20.0 \mu \mathrm{g})$ and $(5.0-$ $50.0 \mu \mathrm{g})$ for FEB and DIC, respectively, were correctly transferred into a series of $10-\mathrm{mL}$ volumetric flasks and methanol was used to complete 
the flasks to the desired volume. The prepared solutions' UV absorption spectra were screened from 200 to $400 \mathrm{~nm}$ using methanol as a blank.

Second Derivative procedures: The amplitude values of second derivative of FEB measured at 353 $\mathrm{nm}$ versus the final drug concentrations in $\mu \mathrm{g} / \mathrm{mL}$ were plotted to get the calibration graph and the regression equation was derived. While DIC measured amplitude values of second derivative of DIC at $246 \mathrm{~nm}$ versus the final drug concentrations in $\mu \mathrm{g} / \mathrm{mL}$ were plotted to get the calibration graph and the regression equation was derived. The parameters of the regression equations were presented in Table 1.

Dual wavelength procedures: The absorbance difference between 299.8 and $265 \mathrm{~nm}$ measured for determination of FEB. While absorbance difference measured between 279.8 and $249.2 \mathrm{~nm}$ was selected for determination of DIC. Calibration curve was designed by plotting the absorbance difference versus drug concentrations in $\mu \mathrm{g} / \mathrm{mL}$ to get the calibration graph and the regression equation was derived. The parameters of the regression equations were presented in Table 1. Ratio subtraction procedures: The calibration graph was generated by plotting the calculated amplitude values of FEB at $316 \mathrm{~nm}$ against the final drug concentrations in $\mu \mathrm{g} / \mathrm{mL}$, and the regression equation was obtained. Also, the calibration graph was generated by plotting the calculated amplitude values of DIC at $283 \mathrm{~nm}$ against the final drug concentrations in $\mu \mathrm{g} / \mathrm{mL}$, and the regression equation was obtained. Table 1.

\subsubsection{Limits of detection and quantitation}

According to ICH guidelines (LOD) and (LOQ) were calculated from the following equations:

$$
\mathrm{LOD}=3.3 \sigma / \mathrm{S} \quad \text { and } \mathrm{LOQ}=10 \sigma / \mathrm{S}
$$

Where $\sigma$ : the residual standard deviation of a regression lines while $S$ : the slope of the calibration curve.

LOD and LOQ values were calculated, and the obtained results showed the sensitivity of the proposed methods as shown in Table 1.

\subsubsection{Accuracy}

The accuracy of the methods was checked by using the proposed procedures to evaluate five different concentrations $(4,8,12,16$ and $20 \mu \mathrm{g} / \mathrm{mL})$ for FEB and $(10,15,20,25,30,35 \mu \mathrm{g} / \mathrm{mL})$ for DIC, each was evaluated in triplicate, in their pure form, on the same day (intra-day) and three days later (interday), and the accuracy was calculated as percent recovery $\% \mathrm{R}$. The $\%$ recoveries for the proposed spectrophotometric methods were in the range of (99.56 to $100.52 \%$ ) for both drugs as shown in Table1.

\subsubsection{Precision}

The precision of the methods was estimated by using the suggested procedures to assess three different concentrations $(4,8$ and 16) $\mu \mathrm{g} / \mathrm{mL}(10,20$ and 30) $\mu \mathrm{g} / \mathrm{mL}$ for FEB and DIC; respectively. Precision was measured as percent relative standard deviation percent RSD for each in triplicate, in their pure state on the same day (intra-day) and three days later (inter-day) as shown in Table 1.

\subsubsection{Robustness}

The robustness of the posited procedures was examined by repeating each procedure with small alterations in the wavelength at which results are obtained $(0.2 \mathrm{~nm})$. No marked changes were observed in the results, confirming robustness of the proposed methods.

Table 1: The regression parameters and validation results for determination of FEB and DIC by the proposed methods

\begin{tabular}{|c|c|c|c|c|c|c|}
\hline \multirow{2}{*}{ Parameter } & \multicolumn{2}{|c|}{${ }^{2} \mathbf{D}$} & \multicolumn{2}{|c|}{ DW } & \multicolumn{2}{|c|}{ RS } \\
\hline & FEB & DIC & FEB & DIC & FEB & DIC \\
\hline Wave length (nm) & 353 & 246 & $(299.8-265)$ & $(279.8-249.2)$ & 316 & 283 \\
\hline Linearity range $\mu \mathrm{g} / \mathrm{mL}$ & $2.0-20.0$ & $5.0-50.0$ & $2.0-20.0$ & $5.0-50.0$ & $2.0-20.0$ & $5.0-50.0$ \\
\hline Slope & 0.0476 & 0.0322 & 0.048 & 0.0296 & 0.0751 & 0.0415 \\
\hline Intercept & 0.0052 & 0.0262 & 0.0074 & 0.0126 & 0.0031 & 0.0205 \\
\hline Determination coefficient ( $\mathrm{r} 2$ ) & 0.9995 & 0.9998 & 0.9997 & 0.9998 & 0.9995 & 0.9999 \\
\hline Accuracy $^{\mathrm{a}} \quad(\% \mathrm{R})$ & 99.78 & 100.05 & 100.17 & 100.52 & 100.05 & 99.56 \\
\hline Inter-day precision ${ }^{\mathrm{b}}$ RSD $\%$ & 0.989 & 1.734 & 1.052 & 0.601 & 0.521 & 0.207 \\
\hline Intra-day precision ${ }^{\mathrm{b}}$ RSD $\%$ & 0.998 & 0.170 & 1.585 & 0.731 & 1.115 & 0.512 \\
\hline LOD $\mu \mathrm{g} / \mathrm{mL}$ & 0.253 & 0.580 & 0.412 & 0.395 & 0.137 & 0.135 \\
\hline LOQ $\mu \mathrm{g} / \mathrm{mL}$ & 0.767 & 1.756 & 1.250 & 1.197 & 0.414 & 0.408 \\
\hline
\end{tabular}

a mean of 5 determinations, ${ }^{\mathrm{b}}$ mean of 3 determination 


\subsubsection{Selectivity}

The specificity of the proposed methods was confirmed by testing them on laboratory-prepared mixtures of FEB and DIC at various concentrations within the range of linearity. Good recoveries were obtained as shown in Table 2.

Table 2: Determination of FEB and DIC in laboratory prepared mixtures by the proposed methods

\begin{tabular}{cccccccc}
\hline \multirow{2}{*}{$\begin{array}{c}\text { Lab prepared mixture } \\
\boldsymbol{\mu g} / \mathbf{m L}\end{array}$} & \multicolumn{2}{c}{${ }^{2} \mathbf{D}$} & \multicolumn{2}{c}{ DW } \\
\cline { 2 - 8 } FEB & DIC & FEB & DIC & FEB & DIC & FEB & DIC \\
\hline 4 & 10 & 100.4 & 99.23 & 101.78 & 98.54 & 101.95 & 101.05 \\
\hline 5 & 12.5 & 98.54 & 98.84 & 101.78 & 99.89 & 97.52 & 99.86 \\
\hline 6 & 15 & 102.08 & 100.44 & 101.77 & 100.75 & 98.57 & 100.55 \\
\hline 8 & 20 & 99.31 & 101.19 & 99.41 & 99.39 & 101.84 & 100.77 \\
\hline 10 & 25 & 101.98 & 98.66 & 98.49 & 101.08 & 98.76 & 99.43 \\
\hline 12 & 30 & 101.27 & 101.84 & 100.53 & 99.47 & 100.88 & 99.51 \\
\hline 10 & 10 & 98.17 & 101.03 & 99.69 & 101.64 & 99.79 & 101.12 \\
\hline 5 & 15 & 102.02 & 99.41 & 97.96 & 98.87 & 101.72 & 98.8 \\
\hline 15 & 5 & 100.93 & 99.42 & 101.34 & 98.24 & 99.67 & 102.06 \\
\hline 10 & 20 & 98.14 & 99.73 & 99.87 & 98.69 & 101.83 & 98.76 \\
\hline \multirow{2}{*}{ Mean $\% \pm$ SD } & 100.28 & 99.98 & 100.26 & 99.35 & 100.25 & 100.19 \\
& & \pm 1.618 & \pm 1.082 & \pm 1.405 & \pm 1.161 & \pm 1.533 & \pm 1.090 \\
\hline
\end{tabular}

\subsubsection{Application in multi-ingredient formula}

For the determination of FEB and DIC in their tablets, the proposed procedures were used. The results were satisfactory and in line with the label argument, suggesting that there was no disruption from excipients or additives. In addition, the standard addition technique was used to verify the specificity of the procedures mentioned. It was carried out by adding known quantities of FEB or DIC in their pure forms to already analyze multi-ingredient formula and the percent recovery $\% \mathrm{R}$ of the pure added concentrations was calculated Table 3 . The obtained results were statistically compared with the results obtained using the reported procedure $^{10}$ which involved RP-HPLC using mixture of $\mathrm{KH}_{2} \mathrm{PO}_{4}(0.02$ $\mathrm{M})$ and sodium hydroxide: acetonitrile: methanol $(35: 9: 56, \mathrm{v} / \mathrm{v} / \mathrm{v})$ as mobile phase. Detection was carried out at $290 \mathrm{~nm}$ is determined in concentration range of $12.5-75 \mu \mathrm{g} / \mathrm{mL}$ and $5-30 \mu \mathrm{g} / \mathrm{mL}$ for DIC \& FEB; respectively. Using the t-test and F-value ${ }^{23}$ at a $95 \%$ confidence level, no major variations were observed, suggesting that the proposed methods for the study of two drugs in their multi-ingredient formula were accurate and precise as shown in Table 4.

Table 3: Determination of FEB and DIC in pharmaceutical dosage forms by the proposed methods and results obtained by standard addition technique.

\begin{tabular}{|c|c|c|c|c|c|c|c|c|c|c|c|}
\hline \multicolumn{3}{|c|}{ Xanfeb DSR ${ }^{\circledR}$} & \multicolumn{3}{|c|}{${ }^{2} \mathrm{D}$} & \multicolumn{3}{|c|}{ DW } & \multicolumn{3}{|c|}{$\mathrm{RS}$} \\
\hline & $\begin{array}{l}\text { Claimed } \\
\text { taken } \\
(\mu \mathrm{g} / \mathrm{ml})\end{array}$ & $\begin{array}{c}\text { Pure } \\
\text { added } \\
(\mu \mathrm{g} / \mathrm{mL})\end{array}$ & $\begin{array}{c}\text { Mean } \% \pm \\
\text { SD }\end{array}$ & $\begin{array}{c}\text { Pure found } \\
(\mu \mathrm{g} / \mathrm{mL})\end{array}$ & $\begin{array}{c}\mathrm{R} \% \text { of pure } \\
\text { added }\end{array}$ & $\begin{array}{c}\text { Mean } \% \pm \\
\text { SD }\end{array}$ & $\begin{array}{c}\text { Pure } \\
\text { found } \\
(\mu \mathrm{g} / \mathrm{mL})\end{array}$ & $\begin{array}{l}\mathrm{R} \% \text { of } \\
\text { pure } \\
\text { added }\end{array}$ & $\begin{array}{c}\text { Mean\% } \\
\pm \mathrm{SD}\end{array}$ & $\begin{array}{c}\text { Pure } \\
\text { found } \\
(\mu \mathrm{g} / \mathrm{mL})\end{array}$ & $\begin{array}{l}\mathrm{R} \% \text { of } \\
\text { pure } \\
\text { added }\end{array}$ \\
\hline \multirow{3}{*}{ FEB } & 4 & 4 & \multirow{3}{*}{$\begin{array}{l}99.78 \pm 1.3 \\
80\end{array}$} & 3.913 & 97.83 & \multirow{3}{*}{$\begin{array}{l}99.81 \pm 1.3 \\
44\end{array}$} & 3.918 & 97.95 & \multirow{3}{*}{$\begin{array}{l}99.85 \pm 1 \\
330\end{array}$} & 3.916 & 97.90 \\
\hline & 4 & 8 & & 7.961 & 99.51 & & 7.966 & 99.58 & & 7.974 & 99.68 \\
\hline & 4 & 12 & & 12.038 & 100.32 & & 12.044 & 100.37 & & 12.035 & 100.29 \\
\hline \multicolumn{4}{|c|}{ Mean $\% \pm S D$} & \multicolumn{3}{|c|}{$99.22 \pm 1.27$} & \multicolumn{3}{|c|}{$99.30 \pm \quad 1.234$} & \multicolumn{2}{|c|}{$99.29 \pm 1.242$} \\
\hline \multirow{3}{*}{ DIC } & 10 & 10 & \multirow{3}{*}{$\begin{array}{l}100.21 \pm 1 . \\
086\end{array}$} & 10.095 & 100.95 & & 10.091 & 100.91 & \multirow{3}{*}{$\begin{array}{l}100.26 \pm \\
0.988\end{array}$} & 10.087 & 100.87 \\
\hline & 10 & 20 & & 19.614 & 98.07 & $100.20 \pm 1$ & 19.626 & 98.13 & & 19.628 & 98.14 \\
\hline & 10 & 30 & & 29.505 & 98.35 & 208 & 29.505 & 98.35 & & 29.496 & 98.32 \\
\hline \multicolumn{4}{|c|}{ Mean $\% \pm$ SD } & \multicolumn{2}{|c|}{$99.12 \pm 1.588$} & & \multicolumn{3}{|c|}{$99.13 \pm 1.545$} & \multicolumn{2}{|c|}{$99.11 \pm 1.527$} \\
\hline
\end{tabular}


Table 4: Statistical comparison for the results obtained by the proposed methods and the reported methods [10] for the analysis of FEB and DIC.

\begin{tabular}{|c|c|c|c|c|c|c|c|c|c|c|c|}
\hline \multicolumn{3}{|c|}{${ }^{2} D$ method } & \multicolumn{3}{|c|}{ DW method } & \multicolumn{3}{|c|}{ RS method } & \multicolumn{3}{|c|}{ Reported method ${ }^{10}$} \\
\hline $\begin{array}{c}\text { Taken } \\
\left(\mu \mathrm{g} \mathrm{mL}^{-1}\right) \\
\end{array}$ & $\begin{array}{l}\text { Found* } \\
(\mu \mathrm{g} / \mathrm{mL})\end{array}$ & $\begin{array}{c}\% \\
\text { Recovery } \\
\end{array}$ & $\begin{array}{c}\text { Taken } \\
(\mu \mathrm{g} / \mathrm{mL})\end{array}$ & $\begin{array}{l}\text { Found* } \\
(\mu \mathrm{g} / \mathrm{mL})\end{array}$ & $\begin{array}{c}\% \\
\text { Recovery } \\
\end{array}$ & $\begin{array}{c}\text { Taken } \\
(\mu \mathrm{g} / \mathrm{mL})\end{array}$ & $\begin{array}{l}\text { Found* } \\
(\mu \mathrm{g} / \mathrm{mL})\end{array}$ & $\begin{array}{c}\% \\
\text { Recovery } \\
\end{array}$ & $\begin{array}{c}\text { Taken } \\
(\mu \mathrm{g} / \mathrm{mL})\end{array}$ & $\begin{array}{l}\text { Found * } \\
(\mu \mathrm{g} / \mathrm{mL})\end{array}$ & $\begin{array}{c}\% \\
\text { Recovery } \\
\end{array}$ \\
\hline 4 & 3.930 & 98.25 & 4 & 4.035 & 100.88 & 4 & 3.935 & 98.38 & 5 & 5.06 & 101.19 \\
\hline 8 & 7.977 & 99.71 & 8 & 7.916 & 98.95 & 8 & 7.967 & 99.59 & 10 & 10.136 & 101.36 \\
\hline 12 & 12.047 & 100.39 & 12 & 11.894 & 99.12 & 12 & 12.049 & 100.41 & 15 & 14.822 & 98.81 \\
\hline 16 & 16.282 & 101.76 & 16 & 16.104 & 100.65 & 16 & 16.291 & 101.82 & 20 & 19.812 & 99.06 \\
\hline 20 & 19.758 & 98.79 & 20 & 19.82 & 99.1 & 20 & 19.808 & 99.04 & 25 & 25.273 & 101.09 \\
\hline
\end{tabular}

\begin{tabular}{|c|c|c|c|c|c|c|c|c|c|c|c|c|}
\hline $\begin{array}{c}\text { Mean \% }{ }^{ \pm} \\
\text {S.D. }\end{array}$ & \multicolumn{3}{|c|}{$99.78 \pm 1.380$} & \multicolumn{3}{|c|}{$99.81 \pm 1.344$} & \multicolumn{3}{|c|}{$99.85 \pm 1.330$} & \multicolumn{3}{|c|}{$100.30 \pm 1.255$} \\
\hline t-test & \multicolumn{3}{|c|}{$0.626(2.306)$} & \multicolumn{3}{|c|}{$0.598(2.306)$} & \multicolumn{3}{|c|}{$0.555(2.306)$} & \multicolumn{3}{|c|}{-} \\
\hline F-test & \multicolumn{3}{|c|}{$1.210(6.388)$} & \multicolumn{3}{|c|}{$1.148(6.388)$} & \multicolumn{3}{|c|}{$1.124(6.388)$} & \multicolumn{3}{|c|}{-} \\
\hline \multirow{5}{*}{ DIC } & 10 & 10.192 & 101.92 & 10 & 10.032 & 100.32 & 10 & 10.186 & 101.86 & 20 & 19.99 & 99.95 \\
\hline & 20 & 19.882 & 99.41 & 20 & 20.27 & 101.35 & 20 & 19.854 & 99.27 & 30 & 29.817 & 99.39 \\
\hline & 25 & 25.168 & 100.67 & 25 & 24.973 & 99.89 & 25 & 25.113 & 100.45 & 40 & 40.268 & 100.67 \\
\hline & 30 & 29.853 & 99.51 & 30 & 29.838 & 99.46 & 30 & 29.973 & 99.91 & 50 & 50.105 & 100.21 \\
\hline & 40 & 39.816 & 99.54 & 40 & 40.104 & 100.26 & 40 & 39.924 & 99.81 & 60 & 59.898 & 99.83 \\
\hline
\end{tabular}

Mean \% \pm

S.D.

$100.21 \pm 1.086$

$100.20 \pm 1.208$

$100.26 \pm 0.988$

$100.01 \pm 0.473$

\begin{tabular}{cccc} 
t-test & $0.378(2.306)$ & $0.371(2.306)$ & $0.510(2.306)$ \\
F-test & $5.262(6.388)$ & $4.722(6.388)$ & $4.354(6.388)$ \\
\hline
\end{tabular}

*Average of three separate determinations. The values between parentheses are the tabulated $\mathrm{t}$ and $\mathrm{F}$ values at $P=0.05^{23}$.

\section{Discussion}

The literature review for the determination of cited drugs includes spectrophotometry ${ }^{4-7}$, Habib et al. ${ }^{4}$ developed spectrophotometric methods for determination FEB in concentration range 2-10 $\mu \mathrm{g} / \mathrm{mL}$ and DIC $2.5-25 \mu \mathrm{g} / \mathrm{mL}$, while linear range of Modi et al. ${ }^{5}$ were $3-15 \mu \mathrm{g} / \mathrm{mL}$ and $6-30 \mu \mathrm{g} / \mathrm{mL}$ for FEB and DIC; respectively, and Derasari et al. ${ }^{6}$ determined FEB and DIC in concentration range 2-9 $\mu \mathrm{g} / \mathrm{mL}$ and $5-22.5 \mu \mathrm{g} / \mathrm{mL}$ for FEB and DIC; respectively, On the other hand, El-Yazbi et al. ${ }^{7}$ developed spectrophotometric methods for determination of FEB and DIC in linear range 214 and $4-18 \mu \mathrm{g} / \mathrm{mL}$ for FEB and DIC; respectively, which give priority of the proposed methods to be determined FEB and DIC in wider range as our linear range $2-20$ and $5-50 \mu \mathrm{g} / \mathrm{mL}$ for FEB and DIC; respectively, comparison between the proposed methods and other spectrophotometric reported methods was presented in table 5. The literature review showed also HPTLC and HPLC methods ${ }^{7-10}$ for the determination of cited drugs, El-Yazbi et al. developed two HPTLC methods and one HPLC method for determination of FEB and DIC ${ }^{7-9}$. In the first one ${ }^{7}$ used chloroform-methanol as mobile phase, in [8] used petroleum ether-chloroform-ethyl acetate-formic acid as mobile phase. While in [9] used methanol-formic acid as mobile phase. Vaibhav et al. ${ }^{10}$ used $\mathrm{KH}_{2} \mathrm{PO}_{4}$ and sodium hydroxide: acetonitrile: methanol as mobile phase. Our methods were found to be simpler, less cost, non-destructive and more ecofriendly than others reported methods.

Zero order spectra of two drugs show severed over lapping (Figure 4). Therefor ${ }^{2} \mathrm{D}$, DW and RS methods were selected for resolving over lapping of two drugs without previous separation. The survey of literature review indicated the application of ${ }^{1} \mathrm{D}$ spectrophotometry for the simultaneous determination of two cited drugs ${ }^{6}$. Hence ${ }^{2} \mathrm{D}$ determination of FEB and DIC. It was noteworthy to mention that although the peak of DIC at $292 \mathrm{~nm}$ is very sensitive however it gave non-linear result. In RS method different concentrations of FEB $(4,8,12,14$ and $20 \mu \mathrm{g} / \mathrm{mL})$ and DIC $(5,10,15$ and $20 \mu \mathrm{g} / \mathrm{mL})$ were tried to choose the best divisor. The best one was $(20 \mu \mathrm{g} / \mathrm{mL})$, as it gave best results in accordance with selectivity and sensitivity. 
Table 5: Comparison for the results obtained by the proposed methods and the reported methods for the analysis of FEB and DIC.

\begin{tabular}{|c|c|c|c|c|c|c|c|c|c|c|}
\hline \multirow{3}{*}{$\begin{array}{c}\text { Parameter } \\
\begin{array}{c}\text { Linearity range } \mu \mathrm{g} / \\
\mathrm{mL}\end{array}\end{array}$} & \multicolumn{2}{|c|}{ Proposed methods } & \multicolumn{2}{|c|}{ Reported method ${ }^{4}$} & \multicolumn{2}{|c|}{ Reported method ${ }^{5}$} & \multicolumn{2}{|c|}{ Reported method ${ }^{6}$} & \multicolumn{2}{|c|}{ Reported method $^{7}$} \\
\hline & FEB & DIC & FEB & DIC & FEB & DIC & FEB & DIC & FEB & DIC \\
\hline & $2-20$ & $5-50$ & $2-10$ & $2.5-25$ & $3-15$ & $6-30$ & $2-9$ & $5-22.5$ & $2-14$ & $4-18$ \\
\hline $\begin{array}{l}\text { Inter-day precision } \\
\text { RSD\%(range) }\end{array}$ & $\begin{array}{c}0.989- \\
1.303 \\
\end{array}$ & $\begin{array}{r}0.601- \\
1.734 \\
\end{array}$ & 0.96 & 1.35 & $\begin{array}{l}0.55- \\
0.95 \\
\end{array}$ & $0.71-1.38$ & $0.30-1.19$ & $0.39-1.08$ & $\begin{array}{l}0.47- \\
2.03 \\
\end{array}$ & $0.83-1.95$ \\
\hline $\begin{array}{l}\text { Intra-day precision } \\
\text { RSD\%(range) }\end{array}$ & $\begin{array}{r}0.744- \\
1.585 \\
\end{array}$ & $\begin{array}{l}0.170- \\
0.731 \\
\end{array}$ & 0.66 & 0.45 & $\begin{array}{l}1.04- \\
1.42 \\
\end{array}$ & $0.88-1.69$ & $0.22-1.07$ & $0.22-1.16$ & $\begin{array}{l}0.34- \\
1.90 \\
\end{array}$ & $1.08-2.11$ \\
\hline$\underset{\text { (range) }}{\mu \mathrm{LO} / \mathrm{mL}}$ & $\begin{array}{l}0.137- \\
0.412 \\
\end{array}$ & $\begin{array}{l}0.135- \\
0.580 \\
\end{array}$ & - & - & $\begin{array}{l}0.02- \\
0.16 \\
\end{array}$ & $0.23-0.80$ & $\begin{array}{l}0.054- \\
0.145 \\
\end{array}$ & $0.145-0.84$ & $\begin{array}{l}0.56- \\
0.58 \\
\end{array}$ & $1.16-1.19$ \\
\hline $\begin{array}{l}\text { LOQ } \mu \mathrm{g} / \mathrm{mL} \\
\quad \text { (range) }\end{array}$ & $\begin{array}{c}0.141- \\
1.250 \\
\end{array}$ & $\begin{array}{l}0.408- \\
1.756 \\
\end{array}$ & - & - & $\begin{array}{l}0.07- \\
0.49 \\
\end{array}$ & $0.70-2.43$ & $\begin{array}{l}0.165- \\
0.439 \\
\end{array}$ & $0.439-2.56$ & $\begin{array}{l}1.87- \\
1.92 \\
\end{array}$ & $\begin{array}{l}3.85- \\
3.96 \\
\end{array}$ \\
\hline
\end{tabular}

\section{Conclusion}

The proposed study describes three different spectrophotometric methods for the simultaneous estimation of FEB and DIC in bulk or in their combination; second derivative, dual wavelength and ratio subtraction methods. The proposed methods are easy, fast, and inexpensive from an economic point of view. They can be taken into account another choice tools for the regular analysis of the two drugs with minimum sample preparation since it takes less time and does not necessitate multiple elaborate treatments or time-consuming extraction procedures.

Funding: The work received no funding.

Conflict of interest The authors declare that there are no conflicts of interest Ethics.

Ethics statement: NA.

Author contribution: Authors AE and FF designed the study and wrote the protocol. SM performed the experimental work and statistical analysis. Authors $\mathrm{AE}$ and FF supervise the analyses of the study. Author SM wrote the first draft of the manuscript and managed literature searches. All authors read and approved the final manuscript.

\section{References}

1. Sweetman SC. Martindale the complete drug reference, 37th ed. The Pharmaceutical Press, London, UK (2011).

2. Edwards NL. Febuxosta a new treatment for hyperuricaemia in gout, Rheumatology. (2009); 48: 15-19.

3. Becker MA, Schumacher HR, Espinoza LR, Wells AF, MacDonald PA and Lioyd E.
The urate-lowering efficacy and safety of febuxostat in the treatment of the hyperuricemia of gout. Arthritis Research and Therapy. (2010); 12(2).

4. Habib I, Rizk M, Abou El-Alamin MM, Imam GS .Simultaeous spectrophotometric determination of febuxostat and diclofenac in pharmaceutical dosage using chemometrics methods, ejbps. (2016); 3 (6): $188-195$.

5. Modi NR, Mothalia CP, Prajapati KR, .Parmar RR, Shah VN , Shah D .Development and validation of spectrophotometric method for simultaneous estimation of diclofenac potassium and febuxostat in tablet dosage forms, Pharma sci. monit, (2013); 4: 268278.

6. Derasari JM, Patel VP. Spectrophotometric determination of febuxostat and diclofenac potassium in their combined dosage form by simultaneous equation and first order derivative methods. Asian J. Chem. (2013); 6: 968-972.

7. El-Yazbi FA, Amin OA, El-Kimary E, Khamis EF, Younis SE. HPTLC and spectrophotometric estimation of febuxostat and diclofenac potassium in their combined tablets J. Chromatogr. Sci. (2016); 54 (7):1146-1152.

8. El-Yazbi FA, Amin OA, El-Kimary E, Khamis EF, Younis SE. High-performance 
thin-layer chromatographic methods for the determination of febuxostat and febuxostat/diclofenac combination in human plasma. J. Chromatogr B Analyt Technol Biomed Life Sci. (2018); 1086:8996.

9. El-Yazbi FA, Amin OA, El-Kimary EI, Khamis EF, Younis SE, Elkhatib MA . A novel HPLC-DAD method for simultaneous determination of febuxostat and diclofenac in biological samples: pharmacokinetic outcomes. Bioanalysis. (2019); 11(1): 41-54.

10. Vaibhav S, Mohit M, Sadhana R, Validation of RP-HPLC for simultaneous estimation of febuxostat and diclofenac potassium in bulk drug and in bilayer tablet formulation, Int. Res. J. Pharm; (2013);4: 103-106.

11. Karpinska J, Basic principles and Analytical Application of derivative spectrophotometry, macro to nano spectroscopy. Dr. Jamal Uddin (Ed.), InTech, DOI: 10.5772/37673. Chapter 13, (2012).

12. Patel NK, Patel KJ, Rajput CG, Rajgor BN, Derivative spectrometry method for chemical analysis: A review. Der Pharmacia Lettre. (2010); 2 (2): 139-150.

13. Padaliya H, Bhati S. Pratik P, Hemant P. Development and validation of second order derivative spectrophotometric method for simultaneous estimation of Paracetamol and Pamabrom in pharmaceutical dosage form. Am J Pharm Tech Res, (2013); 3 (2): 651658.

14. Badran AI, EL-Fatatry H.M. Simultaneous estimation of telmisartan and amlodipine by second derivative spectrophotometric method and first derivative ratiospectrophotometric method. Am J Pharm Tech Res. (2015); 5 (2):172-189.

15. Oza CK, Nijhawan R, Pandya MK, Vyas AJ and Patel AI. Dual wavelength spectrophotometric method for the simultaneous determination of paracetamol and nabumetone in API and in tablet dosage form. Asian J Pharm Anal. (2012); 2 (4): 122-127.

16. Khamar JC and Patel SA. Dual wavelength spectrophotometric method for the simultaneous estimation of rifampicin and piperine in their combined capsule dosage form. Am J Pharm Tech Res. (2012); 2 (3): 653-62. 17. Savithri R, Bindu NS, Bhargavi PS, Theja DH and Ramalingam P. Dual wavelength UV- spectrophotometric method for simultaneous estimation of atorvastatin and ezetimibe in bulk and their combined tablet dosage form. Der Pharm Sinica. (2011); 2 (5): 251-8.

18. El-Ghobashy MR and Abo-Talib NF. Spectrophotometric methods for the simultaneous determination of binary mixture of metronidazole and diloxanide furoate without prior separation. J Adv Res. (2010); 1 (4): 323-9.

19. Darwish HW, Hassan SA, Salem MY and ElZeany BA. Three different spectrophotometric methods manipulating ratio spectra for determination of binary mixture of amlodipine and atorvastatin. Spectrochim Acta A Mol Biomol Spectrosc. 2011; 83 (1): 140-8.

20. Abdel-Gawad SA and Elsherif ZA. Development and validation of spectrophotometric methods simultaneous determination of sitagliptin and simvastatin in binary mixture. Eur J Chem. (2012); 3 (4): 447-54.

21. Abd El Kawy M, El Gindy AE, Hegazy M and Shokry ES. Novel spectrophotometric method for simultaneous determination of two binary mixtures containing hydrochlorothiazide by ratio subtraction. J Appl Sci Res. (2010); 6 (8): 918-26.

22. International Conference on Harmonization (ICH), Technical Requirements for the Registration of Pharmaceutical for Human Use, Validation of Analytical Procedures; Text and methodology Q2 (R1), Geneva, 1, (2005).

23. Miller JC, Miller JN. Statistics and Chemometrics for Analytical Chemistry, 5th edn. (Pearson Education Limited, Harlow, (2005). 